\title{
Implementasi Sistem Informasi Penjualan Produk Elektronik Berbasis Web Dengan Menggunakan Laravel Framework
}

\author{
Tengku Cut Al-Saidina \\ Zulkhaidi \\ Politeknik Pertanian Negeri \\ Samarinda Teknologi Rekayasa \\ Perangkat Lunak Manajemen \\ Pertanian \\ Samarinda, Kalimantan Timur \\ tcazme01@gmail.com
}

\author{
Yulianto \\ Teknologi Rekayasa Perangkat \\ Lunak \\ Politeknik Pertanian Negeri \\ Samarinda Manajemen Pertanian \\ Samarinda, Kalimantan Timur \\ yulianto.tile@yahoo.com
}

\author{
Suswanto \\ Teknologi Rekayasa Perangkat \\ Lunak \\ Politeknik Pertanian Negeri \\ Samarinda Manajemen Pertanian \\ Samarinda, Kalimantan Timur \\ suswanto.attala@gmail.com
}

\begin{abstract}
Abstrak - Perkembangan teknologi terutama teknologi berbasiskan internet semakin meningkat termasuk teknologi sistem informasi penjualan atau biasa disebut web toko online yang dapat digunakan untuk melakukan pembelian produk hanya dengan masuk ke dalam web, memilih barang yang disukai dan membayar dengan menggunakan sistem transfer maka barang akan diantarkan ke alamat yang dituju. Pada negara Indonesia perkembangan sistem informasi penjualan sudah sangat wajar dan akan terus meningkat pesat dengan tersebarnya internet ke seluruh pelosok daerah. Hasil penelitian menunjukkan bahwa pada pembuatan sistem informasi penjualan dengan menggunakan laravel framework memiliki kemudahan karena laravel telah menyediakan plugin yang dapat digunakan dalam membantu pembangunan sistem yang kompleks dan pada perancangan database tidak menjadi kendala dikarenakan laravel telah memisahkan perancangan database dari desain tampilan. Pada sistem informasi penjualan juga diketahui memiliki 3 aspek penting yaitu: menu cart dan login, admin dashboard, dan halaman payment.
\end{abstract}

Kata Kunci - Sistem Informasi Penjualan, PHP, Laravel, Framework, System Development Life Cycle.

\section{PENDAHULUAN}

Sistem informasi yaitu suatu sistem yang menyediakan informasi untuk manajemen dalam mengambil keputusan dan juga untuk menjalankan operasional perusahaan, di mana sistem tersebut merupakan kombinasi dari orang-orang, teknologi informasi dan prosedur-prosedur yang terorganisasi (Anggraeni, 2017).

Sistem informasi tidak pernah lepas dengan internet yang menyediakan sumber informasi yang sangat banyak, dengan adanya sistem informasi pada suatu usaha dapat menjamin kualitas informasi yang disajikan dan dapat mengambil keputusan berdasarkan informasi tersebut. Seiring perkembangan teknologi maka kebutuhan akan informasi yang cepat, tepat dan akurat sangat diperlukan. Karena itu, keberadaan sistem informasi sudah menjadi kebutuhan mutlak bagi suatu usaha dalam menjalankan bisnisnya.

Dalam perkembangan teknologi saat sekarang sistem informasi mengambil peranan yang penting dalam menyajikan data yang tanpa kita sadari menjadi bagian kehidupan kita, seperti sistem informasi penjualan barang yang membantu kita membeli keperluan kita tanpa harus keluar rumah dengan memiliki akses internet kita dapat mengakses sistem informasi penjualan seperti Bukalapak, Tokopedia atau Shopee yang menyediakan berbagai macam barang kebutuhan.

Sistem informasi sudah dikembang sejak awal tahun 1960-an dan banyak digunakan untuk otomatisasi proses bisnis yang membantu dari sudut pandang data. Pada tahun 1970-an teknologi database berkembang cukup cepat, sehingga fokus utama sistem informasi saat itu adalah penyimpanan dan pengaksesan data. Pada saat sekarang sistem informasi sudah dapat diintegrasikan dengan bermacam-macam sistem yang lain agar kinerja menjadi lebih efisein.

Dengan kemajuan teknologi yang telah tersedia seperti smartphone yang dapat mengakses internet dengan mudah maka membuat sistem informasi penjualan jauh lebih mudah dalam penjualan, penulis akan membuat toko online yang menjual barang elektronik dikarenakan barang elektronik banyak diminati dengan perkembangan zaman yang ada.

Berdasarkan latar belakang yang telah dipaparkan tersebut, maka permasalahan yang dapat dirumuskan sebagai berikut:

1. Bagaimana kinerja web sistem informasi penjualan?

2. Bagaimana teknologi yang digunakan dalam membuat web sistem informasi penjualan bekerja?

3. Apa saja fungsi utama untuk membuat sistem informasi penjualan dapat digunakan oleh user?

Mengingat permasalahan yang tercakup dalam penelitian yang sangat luas, karena keterbatasan masalah, penulis memiliki keterbatasan dalam meneliti, maka penulis batasi pada:

1. Pembuatan web penjualan menggunakan Laravel Framework.

2. Sistem penyimpanan data produk menggunakan $M y S Q L$. 
3. Web sistem informasi penjualan terdapat login pengguna dan login admin.

4. Web sistem informasi penjualan terdapat keranjang belanja.

5. Terdapat dashboard admin untuk mengetahui jumlah transaksi pengguna.

Tujuan dari penelitian ini adalah:

1. Mengetahui alur kerja web sistem informasi penjualan produk elektronik.

2. Mengetahui teknologi yang digunakan dalam membuat web sistem informasi penjualan produk elektronik.

3. Mengetahui fungsi utama yang digunakan di dalam web sistem informasi penjualan produk elektronik.

\section{TINJAUAN PUSTAKA}

A. Sistem

Sistem adalah kumpulan orang yang saling bekerja sama dengan ketentuan-ketentuan aturan yang sistematis dan terstruktur untuk membentuk suatu kesatuan yang melaksanakan suatu fungsi untuk mencapai tujuan. Sistem memiliki beberapa karakteristik atau sifat yang terdiri dari komponen sistem, batasan sistem, lingkungan luar sistem, penghubung sistem, masukan sistem, keluaran sistem, pengolahan sistem dan sasaran sistem (Anggreani, 2017).

Suatu sistem dibentuk oleh unsur-unsur tertentu. Setiap sistem terdiri dari empat unsur, yaitu:

1. Obyek, di dalam sistem terdapat sekumpulan obyek (fisik/ abstrak) dalam bentuk elemen, bagian, atau variabel.

2. Atribut, sesuatu yang menentukan mutu atau sifat kepemilikan suatu sistem dan obyeknya.

3. Hubungan internal, setiap elemen saling terikat menjadi satu kesatuan.

4. Lingkungan, tempat atau wilayah dimana sistem berada.

Sedangkan elemen pembentuk suatu sistem dapat dibagi menjadi tujuh bagian, yaitu:

1. Tujuan, sistem dibuat untuk mencapai tujuan (output) tertentu yang ingin dicapai.

2. Masukan, semuanya yang masuk ke dalam sistem akan diproses, baik itu obyek fisik maupun abstrak.

3. Proses, yaitu transformasi dari masukan menjadi keluaran yang lebih memiliki nilai, misalnya produk atau informasi. Namun juga bisa dapat berupa hal yang tak berguna, misalnya limbah.

4. Keluaran, ini adalah hasil dari pemrosesan dimana wujudnya bisa dalam bentuk informasi, saran, cetakan laporan, produk, dan lain-lain.

5. Batas, sesuatu yang memisahkan antara sistem dan daerah di luar sistem. Dalam hal batas akan menentukan konfigurasi, ruang lingkup, dan halhal lainnya.

6. Pengendalian dan Umpan Balik, mekanismenya dapat dilakukan dengan memakai feedback terhadap keluaran untuk mengendalikan masukan maupun proses.
7. Lingkungan, segala sesuaut di luar sistem yang berpengaruh pada sistem, baik menguntungkan maupun merugikan.

B. Informasi

Informasi dapat didefinisikan sebagai hasil dari pengolahan data dalam suatu bentuk yang lebih berguna dan lebih berarti bagi penerimanya yang menggambarkan suatu kejadian-kejadian yang nyata yang digunakan untuk pengambilan keputusan. Informasi merupakan data yang telah diklasifikasikan atau diolah atau diinterpretasikan untuk digunakan dalam proses pengambilan keputusan (Anggreani, 2017).

\section{Sistem Informasi}

Sistem informasi adalah suatu sistem dalam suatu organinasi yang mempertemukan kebutuhan pengolahan transaksi harian yang mendukung fungsi operasi organisasi yang bersifat manajerial dengan kegiatan strategi dari suatu organisasi untuk dapat menyediakan kepada pihak luar tertentu dengan informasi yang diperlukan untuk pengambilan keputusan.

Sistem informasi dalam suatu organisasi dapat dikatakan sebagai suatu sistem yang menyediakan informasi bagi semua tingkatan dalam organisasi tersebut kapan saja diperlukan. Sistem ini menyimpan, mengambil, mengubah, mengolah dan mengkomunikasikan informasi yang diterima dengan menggunakan sistem informasi atau peralatan sistem lainnya (Anggreani, 2017).

\section{Data}

Data adalah deskripsi tentang benda, kejadian, aktivitas, dan transaksi, yang mempunyai makna atau tidak berpengaruh secara langsung kepada pemakai (Anggreani, 2017).

Beberapa contoh tipe data :

a. Data yang terformat adalah data dengan suatu format tertentu. Misalnya data yang menyatakan tanggal atau jam, atau menyatakan nilai mata uang.

b. Teks adalah sederetan huruf, angka, dan symbol-simbol khusus (misanya + dan $\$$ ) yang kombinasinya tidak tergantung pada masingmasing item secara individual. Contoh teks adalah artikel koran.

c. Citra (image) adalah data dalam bentuk gambar. Citra dapat berupa foto, grafik, hasil rontgen, dan tanda tangan, dan lain-lain.

d. Audio adalah data dalam bentuk suara. Contoh data audio: instrumen musik, suara orang/suara binatang, gemericik air, dan detak jantung.

e. Video menyatakan data dalam bentuk sejumlah gambar yang bergerak dan bisa saja dilengkapi dengan suara. Video dapat digunakan untuk mengabadikan suatu kejadian/aktivitas. 


\section{E. Internet}

Internet adalah rangkaian hubungan jaringan computer yang dapat diakses secara umum diseluruh dunia, yang mengirimkan data dalam bentuk paket data berdasarkan standar Internet Protocol (IP). Lebih dalam lagi, internet adalah kumpulan jaringan dari jaringan-jaringan komputer dunia yang terdiri dari jutaan unit-unit kecil, seperti jaringan pendidikan, jaringan bisnis, jaringan pemerintahan, dan lain-lain, yang secara bersama menyediakan layanan informasi seperti e-mail, online chat, transfer file, dan saling keterhubungan (linked) antara satu halaman web dengan sumber halaman web yang lainnya (Yuhefizar, 2008).

Fungsi internet dapat digunakan sebagai sarana komunikasi tanpa batas, dan juga sebagai sumber informasi dan pengetahuan di internet ini didapatkan dari berbagai banyaknya website yang menyediakan data yang lengkap. Selain itu, internet juga merupakan media untuk berpromosi baik itu bisnis secara online, tapi tidak hanya itu. Internet juga bisa dijadikan sebagai sumber tempat hiburan, Anda bisa mendapatkan apa saja mulai dari Video, musik, gambar dan sebagainya.

\section{F. Laravel}

Laravel adalah sebuah framework yang digunakan untuk web development di PHP. Umur framework ini, terbilang masih baru (walaupun sudah mulai beranjak ke versi 5), dan mungkin seumuran dengan PhalconPHP (Hamdani, 2015).

\section{G. Framework}

Framework adalah sebuah software untuk memudahkan para programmer untuk membuat sebuah aplikasi web yang di dalam nya ada berbagai fungsi diantaranya plugin, dan konsep untuk membentuk suatu sistem tertentu agar tersusun dan tersetruktur dengan rapih.

Dengan menggunakan framework bukan berarti akan terbebas dengan pengkodean. Karena sebagai seorang pengguna framework haruslah menggunakan fungsi - fungsi dan variabel yang ada di dalam sebuah framework yang kita gunakan. Untuk saat ini framework $P H P$ terdiri dari:

$\begin{array}{ll}\text { - } & \text { Laravel } \\ \text { - } & \text { Yii } \\ \text { - } & \text { Code Igniter } \\ \text { - } & \text { Symfoni } \\ \text { - } & \text { Cakd Framework } \\ \text { - } & \text { Fuel PHP } \\ \text { - } & \text { DLL }\end{array}$

\section{H. Sistem Informasi Penjualan}

Sistem Informasi Penjualan adalah sub sistem informasi bisnis yang mencakup kumpulan prosedure yang melaksanakan, mencatat, mengkalkulasi, membuat dokumen dan informasi penjualan untuk keperluan manajemen dan bagian lain yang berkepentingan, mulai dari diterimanya Order penjualan sampai mencatat timbulnya Tagihan/Piutang Dagang.

\section{METODE PENELITIAN}

\section{A. Prosedur Penelitian}

Penelitian ini menggunakan metode System Development Life Cycle (SDLC) dalam perancangan sistem yang merupakan suatu siklus pengembangan sistem yang digunakan untuk menggambarkan beberapa tahapan dalam proses pengembangan. Diagram alir penelitian ini selengkapnya bisa dilihat pada Gambar 1 .

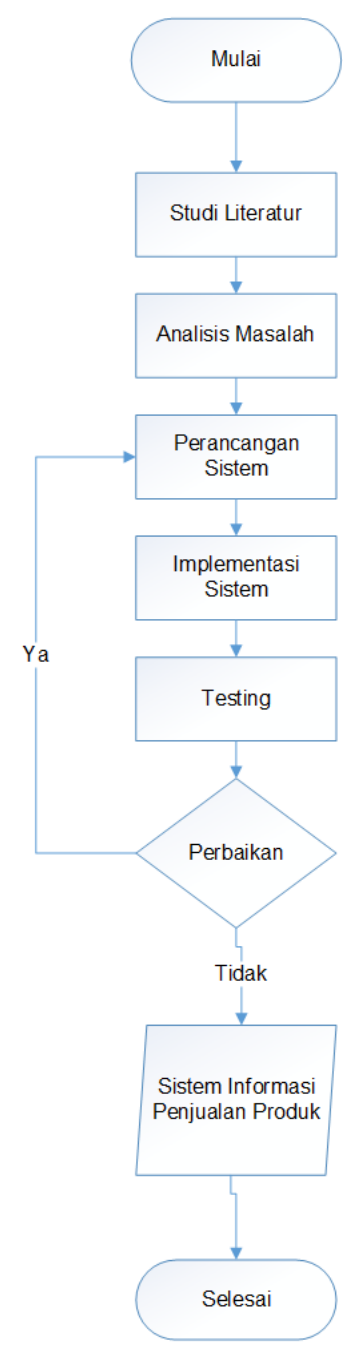

Gambar 1. Prosedur Penelitian

\section{B. Perancangan Sistem}

\section{1) Data Flow Diagram Level 0}

Diagram level 0 pada sistem yang akan dibuat ini menggambarkan proses aliran data secara umum, dimana proses sistem informasi penjualan terdapat sumber serta tujuan dari yang akan di proses secara rinci hingga dapat menggambarkan aliran data yang akan diproses. 


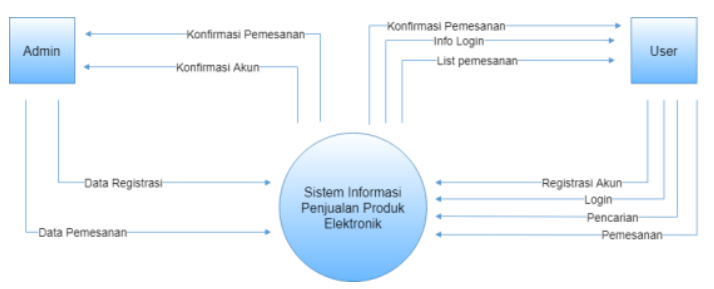

Gambar 2. DFD Level 0

2) Entity Relationship Diagram

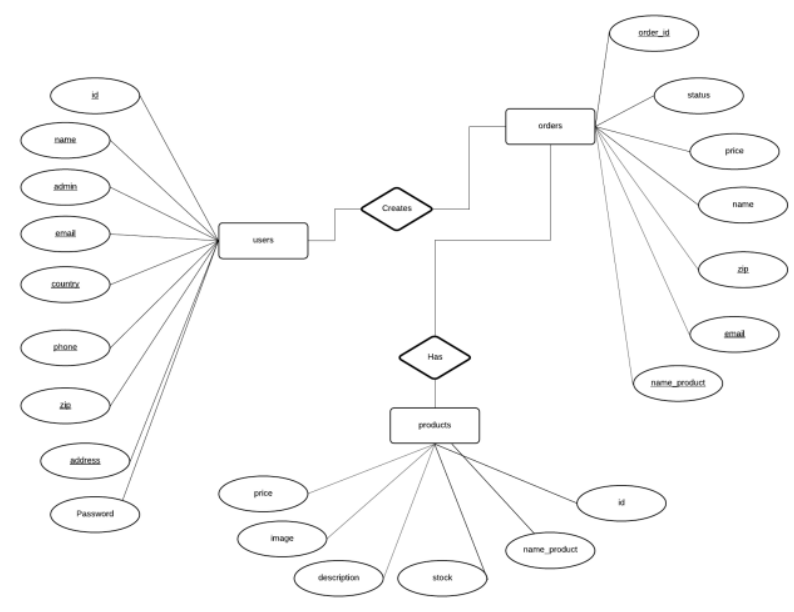

Gambar 3. ERD

C. Rancangan User Interface

1) Desain Tampilan Home

Tampilan Home merupakan tampilan awal pada sistem informasi penjualan yang menampilkan produk yang akan dijual.

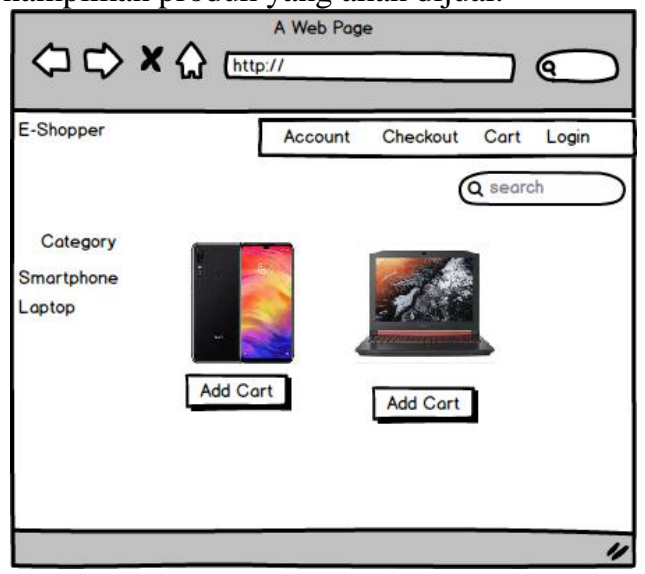

Gambar 3. Desain Tampilan Home

2) Desain Tampilan Login

Tampilan login adalah tampilan yang digunakan oleh user untuk masuk ke dalam sistem informasi penjualan menjadi member.

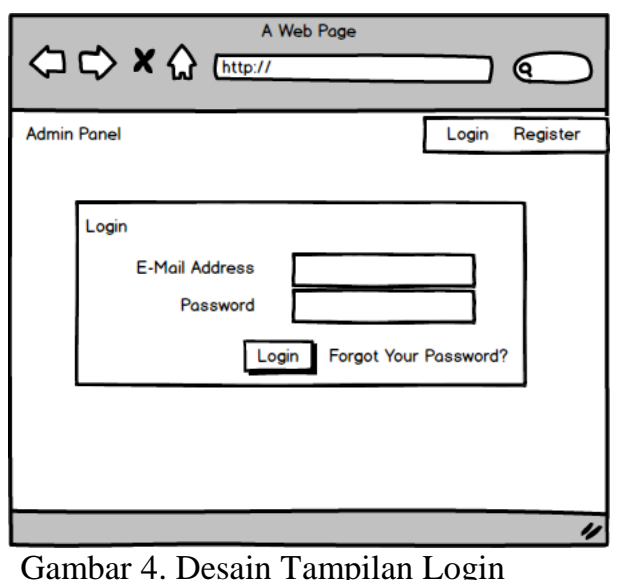

3) Desain Tampilan Admin Dashboard

Tampilan admin dashboard adalah tampilan yang digunakan oleh admin untuk melakukan penambahan produk dan juga mengatur user.

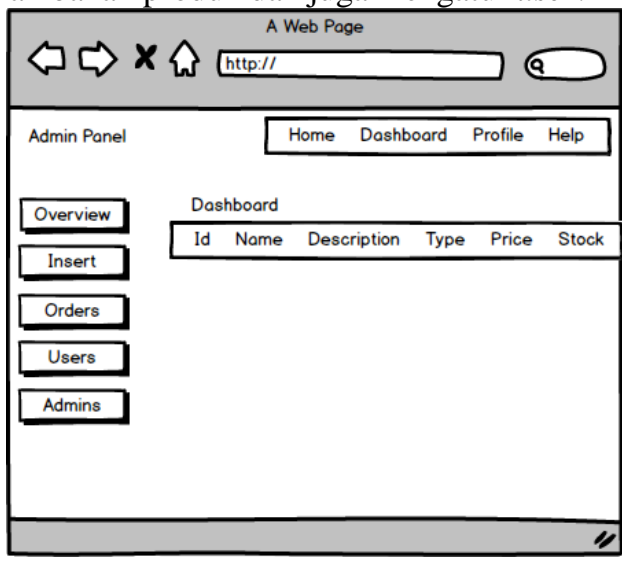

Gambar 5. Desain Tampilan Admin Dashboard

4) Desain Tampilan Cart

Tampilan cart adalah user memasukkan produk ke dalam keranjang belanja yang akan dibeli.

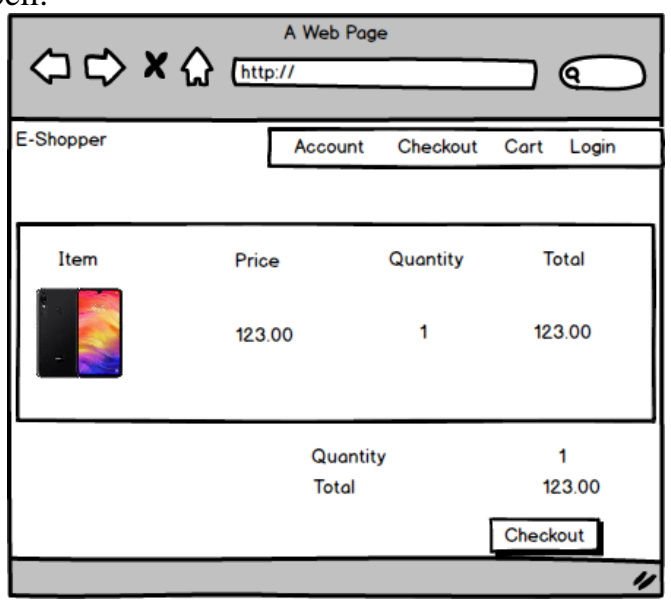

Gambar 6. Desain Tampilan Cart

5) Desain Tampilan Payment

Desain payment adalah tampilan pembayaran pada user, jika user telah melakukan pembayaran maka tinggal menekan tombol selesai transaksi. 


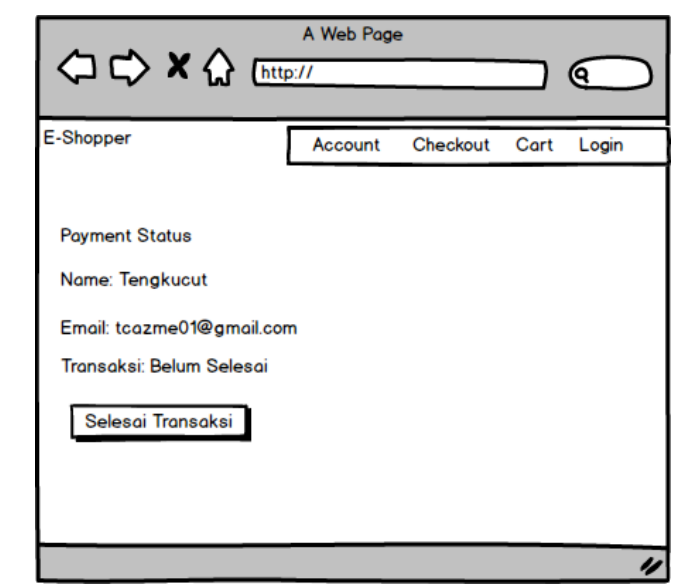

Gambar 7. Desain Tampilan Payment

\section{HASIL DAN PEMBAHASAN}

\section{A. Hasil Pengembangan Sistem}

1) Halaman Home

Halaman home merupakan halaman pertama yang akan ditampilkan dalam web toko online, pada tampilan home terdapat produk elektronik yang dijual dalam toko online yang dapat dibeli dengan menekan add to cart yang akan masuk ke dalam menu cart.

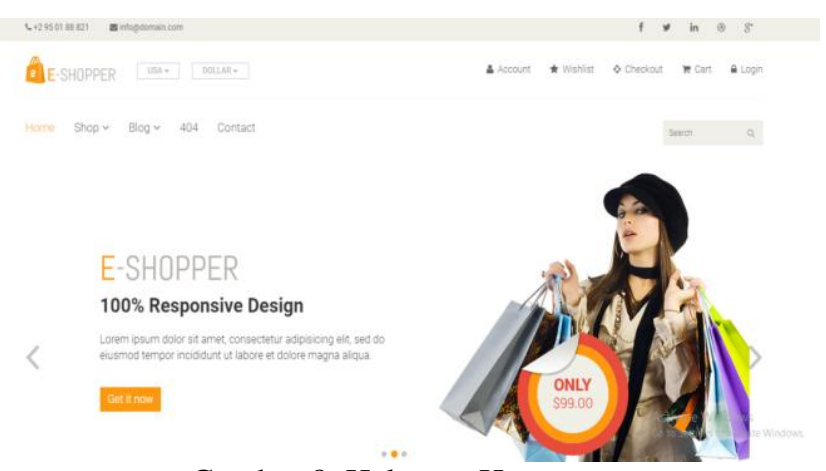

Gambar 8. Halaman Home

\section{2) Halaman Login}

Sebelum dapat membeli produk elektronik harus melakukan login atau register akun agar sistem dapat melakukan verfikasi akun yang akan memasukkan data produk ke dalam database.

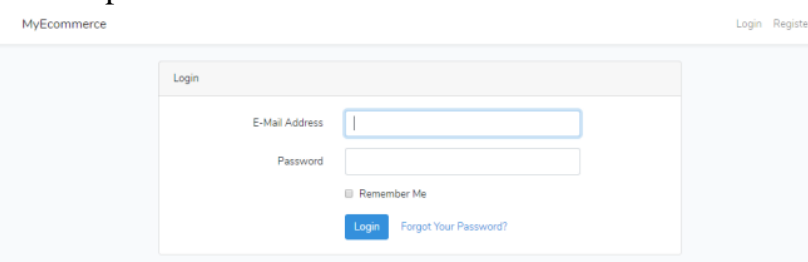

Gambar 9. Halaman Login

3) Halaman Cart

Cart merupakan halaman menu yang menyimpan semua daftar pembelian yang akan dibeli dalam sekali transaksi, untuk dapat masuk ke dalam halaman menu cart user harus menekan add to cart pada produk yang akan dibeli dan masuk ke dalam cart. Semua produk akan diproses saat user menekan button checkout untuk melanjutkan ke transaksi berikutnya.

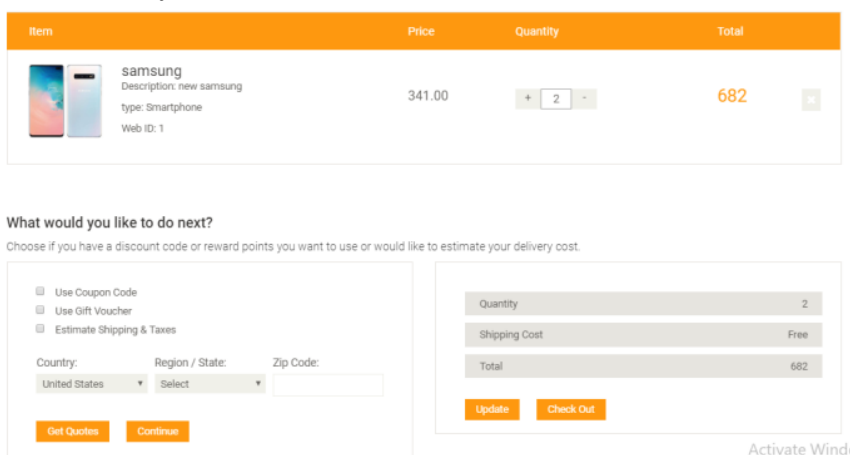

Gambar 10. Halaman Cart

\section{4) Halaman Checkout}

Pada halaman hasil terdapat tabel hasil konversi alternatif yang telah diinputkan, tabel normalisasi, tabel perkalian bobot, tabel nilai preferensi, dan tabel perankingan. Pada halaman cart terdapat button checkout yang akan masuk ke transaksi berikutnya yaitu halaman checkout yang akan menampilkan form data yang harus diisi oleh user untuk sebagai data pengiriman produk, setelah selesai mengisi form makan tekan button proceed to payment untuk masuk ke bagian payment.

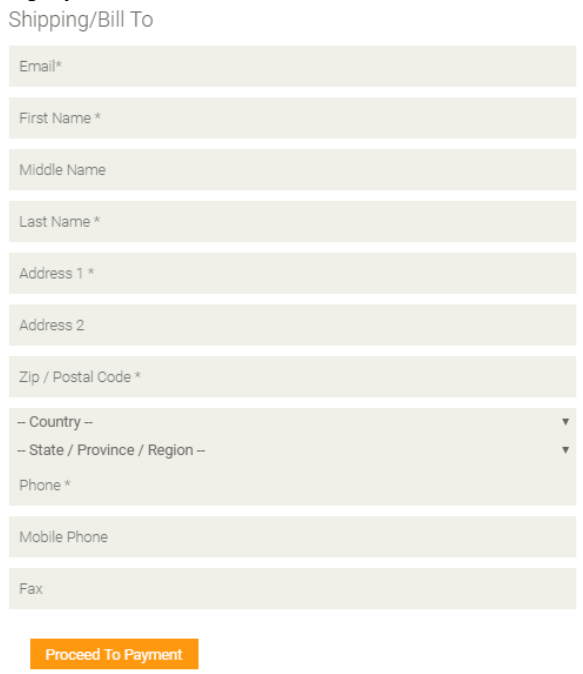

Gambar 11. Halaman Checkout

\section{5) Halaman Payment}

Pada halaman payment akan terdapat data user dan juga status pembayar. Terdapat no rekening toko online untuk melakukan pembayaran, jika user selesai melakukan pembayaran maka tekan button selesai transaksi. 


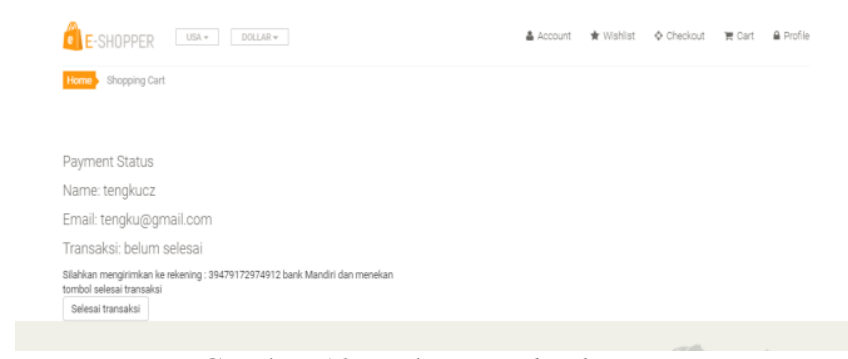

Gambar 12. Halaman Checkout

\section{6) Halaman Admin}

Halaman admin berisi 3 menu yaitu overview, insert dan Orders pada tiap menu memiliki kegunaan masing-masing yang mendukung toko online.

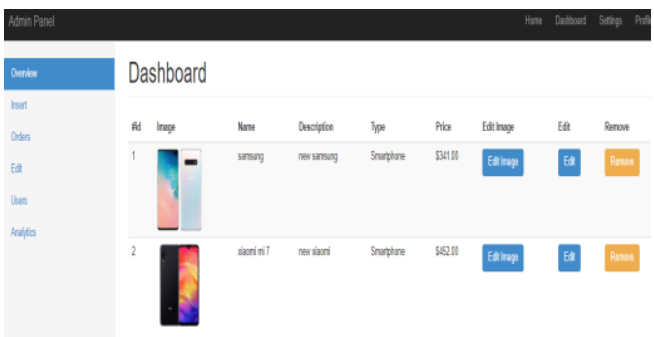

Gambar 13. Halaman Admin

\section{KESIMPULAN}

Implementasi sistem informasi penjualan memiliki tiga fungsi utama meliputi: pertama, menu login dan тепи cart agar pengguna dapat menyimpan produk dan juga menghitung total semua harga produk yang ingin dibeli. Kedua, admin dashboard agar lebih memudahkan dalam mengelola sistem. Ketiga, halaman payment agar user dapat memberikan informasi tentang pembayaran.

Menggunakan Laravel Framework lebih memudahkan dalam membangun sistem informasi penjualan karena telah banyak menyediakan plugin yang dapat membantu pembangunan sistem tanpa harus membangun ulang sistem yang akan memakan waktu lebih lama.

Adapun saran-saran dari penulis untuk sistem ini adalah sebagai berikut:

1. Dalam pembangunan sistem informasi database adalah hal yang penting karena semua data dalam sistem tersimpan ke dalam database dan diolah didalam database maka lebih baik melakukan desain database lebih diutamakan sebelum melakukan desain tampilan.

2. Pada sistem pembayaran sebaiknya menggunakan sistem seperti paypal dan pembayaran dengan menggunakan Application Programming Interface (API) bank. Sistem dapat ditambahkan dengan memasukkan API jasa kurir agar user mengetahui berapa harga pengantaran produk.

\section{DAFTAR PUSTAKA}

Dadan Hamdani. 2015. Belajar Laravel Untuk Pemula.

Delia Mediana dan Andi Iwan Nurhidayat. 2018. Rancangan Bangun Aplikasi HelpDesk(A-Desk) Berbasis Web Menggunakan Framework Laravel (Studi Kasus : PDAM Surya Sembada Kota Surabaya). Jurnal Manajemen Informatika. Vol. 8, No. 2.

Deni Apriadi dan Arie Yandi Saputra. 2017. ECommerce Berbasis Marketplace Dalam Upaya Mempersingkat Distribusi Penjualan Hasil Pertanian. Jurnal Resti.Vol. 1, No. 2.

Elisabet Yunaeti Anggreani dan Rita Irviani. 2017. Pengantar Sistem Informasi.CV. ANDI OFFSET, Yogyakarta.

Hanif Al Fatta. 2007. Analisis dan Perancangan Sistem Informasi untuk Keunggulan Bersaing Perusahaan dan Organisasi Modern. CV. ANDI OFFSET, Yogyakarta.

Oktavian Diar Puji. 2010. Menjadi Programmer Jempolan Menggunakan PHP. MediaKom, Yogyakarta.

Radiant Victor Imbar dan Eric Tirta. 2007. Analisa, Perancangan dan Implementasi Sistem Informasi Penjualan Pelumas (Studi Kasus : Perusahaan PT. Pro Roll International). Jurnal Informatika. Vol. 3, No. 1.

Radiant Victor Imbar dan Eric Tirta. 2007. Analisa, Perancangan dan Implementasi Sistem Informasi Penjualan Pelumas (Studi Kasus : Perusahaan PT. Pro Roll International). Jurnal Informatika. Vol. 3, No. 1.

Yuhefizar. 2008. 10 Jam Menguasai Internet Teknologi dan Aplikasinya. PT. Elex Media Komputindo, Jakarta. 